\title{
$\begin{array}{ll}\text { Research Square } & \text { Preprints are preliminary reports that have not undergone peer review. } \\ \text { They should not be considered conclusive, used to inform clinical practice, } & \text { or referenced by the media as validated information }\end{array}$

\section{C-Reactive Protein Level Predicts Need For Medical Intervention In Pregnant Women With SARS-CoV2 Infection: A Retrospective Study}

\section{Ryutaro Yamamoto}

Hokkaido University Graduate School of Medicine

Hiroshi Asano

Hokkaido University Graduate School of Medicine

Takeshi Umazume ( $\square$ takeuma@med.hokudai.ac.jp )

Hokkaido University Graduate School of Medicine

Masato Takaoka

Hokkaido University Graduate School of Medicine

Kiwamu Noshiro

Hokkaido University Graduate School of Medicine

Yoshihiro Saito

Hokkaido University Graduate School of Medicine

Kinuko Nakagawa

Hokkaido University Graduate School of Medicine

Kentaro Chiba

Hokkaido University Graduate School of Medicine

Sho Nakakubo

Hokkaido University Graduate School of Medicine

Yasuyuki Nasuhara

Hokkaido University Hospital

Satoshi Konno

Hokkaido University Graduate School of Medicine

Hidemichi Watari

Hokkaido University Graduate School of Medicine

\section{Research Article}

Keywords: Covid-19, pregnant women, C-reactive protein

Posted Date: July 22nd, 2021

DOl: https://doi.org/10.21203/rs.3.rs-669127/v1 
License: (c) (i) This work is licensed under a Creative Commons Attribution 4.0 International License. Read Full License

Version of Record: A version of this preprint was published at Journal of Obstetrics and Gynaecology Research on February 15th, 2022. See the published version at https://doi.org/10.1111/jog.15181. 


\section{Abstract}

\section{Background}

During the Coronavirus disease 2019 (COVID-19) pandemic, many hospitals experienced a shortage of hospital beds. To make effective use of the limited available hospital space during the pandemic, we conducted this study to investigate the laboratory indices that identify pregnant women with SARS-CoV2 infection who require medical intervention.

\section{Methods}

We carried out a retrospective analysis of pregnant women positive for COVID-19 who were admitted to Hokkaido University Hospital from September 2020 to June 2021. Medical interventions included oxygen supplementation, systemic corticosteroids, or supplemental liquids to treat infection-related symptoms.

\section{Results}

Forty-two infected pregnant patients were admitted to the hospital, half of whom required medical intervention $(n=21)$. Fever, C-reactive protein, and platelet count are all associated with need for medical intervention. Of the 32 patients with a fever of $\geq 37.5^{\circ} \mathrm{C}$ on days $0-3$ after onset of syndromes, $22(69 \%)$ continued to have a fever on days $4-6$, of which 19 (86.4\%) required medical intervention. C-reactive protein level and platelet count on days 4-6 predicted the presence or absence of medical intervention (area under the receiver operating characteristic curve $=0.913$, and 0.856 , respectively), with a sensitivity of $81 \%$ and specificity of $100 \%$ at a C-reactive protein cutoff of $1.28 \mathrm{mg} / \mathrm{dL}$, with a sensitivity of $75 \%$ and specificity of $87 \%$ at a platelet count cutoff of $16.3 \times 10^{4} / \mu \mathrm{L}$.

\section{Conclusions}

The need for medical intervention in pregnant patients can be predicted with high accuracy using a Creactive protein cutoff of $1.28 \mathrm{mg} / \mathrm{dL}$ on days $4-6$ after onset of syndromes. The presence of fever also may be an easy marker for selecting subjects who need or will need therapeutic intervention. These could be an effective triage method to determine appropriate indications for the hospitalization of pregnant women in future outbreaks.

\section{Background}

Since the first case of COVID-19 infection in Sapporo City in February 2020, there were four outbreak spikes. Each spike was traced to a large social event such as the Sapporo Snow Festival in 2020 or a long national holiday. At each spike, there was a subsequent declaration of a state of emergency by the government to attempt to limit further spread of the infection [1]. Furthermore, due to the long national holiday at the beginning of May in 2021, with an increase in the more contagious N501Y mutant [2], we experienced the largest outbreak (the fourth spike) from the middle of May through the middle of June 
[3]. Many patients were required to stay home or in accommodation facilities, even in a state of hypoxemia, due to the lack of available hospital wards.

The Sapporo City administration made adjustments to the guidelines of medical facilities; admission of patients with COVID-19 should be based on severity and state of infection. After the initial phase of the third spike, infected individuals, including pregnant women, whose general condition was considered good, were not admitted to the hospital due to the lack of available space. The fourth wave was more serious, in this critical situation in Sapporo City, Hokkaido University Hospital admitted all pregnant women positive for SARS-CoV2 starting in May. Additionally, deliveries for women without SARS-CoV2 infection were halted in Hokkaido University Hospital.

The number of infected pregnant women decreased at the time this manuscript was written (end of June, 2021), probably due to the effect of government restrictions on the movement of people outside their homes. However, another larger spike may occur in the near future, leading to a decrease in free hospital beds. In preparation for this eventuality, we sought to identify factors that would aid the triage of pregnant women positive for SARS-CoV2 who require therapeutic intervention and admission to the hospital. In this study, we first retrospectively reviewed the records of pregnant women positive for SARSCoV2 who were admitted to Hokkaido University Hospital to identify the background and clinical characteristics of these patients. We then investigated laboratory indices that could be useful for selecting subjects who require or will require admittance to the hospital to receive therapeutic intervention.

\section{Methods}

\section{Patients}

This was a single-center, retrospective observational study approved by the Hokkaido University Hospital Division of Clinical Research Administration (No. \#020-0107). The study included pregnant women diagnosed with COVID-19 in the third spike of infections peaked in January 2021 and in the fourth spike peaked in early June 2021 who were admitted to the Hokkaido University Hospital. A definitive diagnosis of COVID-19 was defined as a positive nasal swab or saliva specimen by polymerase chain reaction analysis. The treatment strategy followed the official Japanese guidelines of the Ministry of Health, Labor, and Welfare [4]. Demographic characteristics (age and sex) and clinical data (referral source, symptoms, days from onset, comorbidities, and laboratory findings) were collected from medical records by the investigators.

\section{Therapeutic intervention for subjects}

We defined "therapeutic intervention" as the following:

1) Oxygen supplementation

2) 1) + Systemic corticosteroids 
3) 2) + Supplemental liquids due to infection-related symptoms such as high fever and low appetite.

These three conditions were assigned as the primary outcomes of this study. Each treatment decision was finalized after discussions with a respiratory physician for oxygen supplementation and with three obstetricians for supplemental liquids. Regardless of severity, intravenous or subcutaneous heparin was administered to all subjects (10,000 IU/day). None of the subjects were vaccinated against COVID-19.

\section{Biochemical procedures}

Blood samples were sent to the hospital's clinical laboratory immediately after collection and were assayed within $2 \mathrm{~h}$ of collection after storage at room temperature. The $\mathrm{C}$-reactive protein (CRP) and Ddimer levels were measured by latex immunoturbidimetry assay (latro-CRP-EX, LSI Medience, Tokyo, Japan; Riasauto-Ddimer-Neo, Sysmex, Kobe, Japan). Lactate dehydrogenase (LDH) was measured by International Federation of Clinical Chemistry method (Serotec LD-IF, SEROTEC, Sapporo, Japan).

\section{Statistical analysis}

All categorical variables were compared for their association with the study outcomes using Fisher's exact test, and continuous variables were compared using a $t$-test or Mann-Whitney $U$ test as appropriate. Continuous data are expressed as the mean (range) or median (range). Individual risk factors were assessed for their prediction of therapeutic intervention by estimating the area under the curve (AUC) of receiver operating characteristic curves. Risk factors for which the AUC was $>0.8$ were reviewed to derive their clinical relevance for inclusion in the prediction model. Categorical data are expressed as proportions. JMP (SAS Institute Inc., Cary, NC, USA) and Prism 8 (GraphPad Software, San Diego, CA, USA) were used for statistical analyses.

\section{Results}

\section{Characteristics and clinical information}

At Hokkaido University Hospital, five pregnant patients infected with COVID-19 were admitted during the third wave and 37 during the fourth wave (Table 1, Fig. 1). There were no differences in age, body mass index, or days from onset to hospital admission between the groups that required and did not require medical intervention. The number of weeks of pregnancy tended to be higher in the group that required medical intervention $(P=0.078)$, but there was no difference in obstetric complications between the groups. Of the 21 patients receiving medical intervention, 20 (95\%) received supplemental fluids, 13 (62\%) received oxygen, $10(48 \%)$ received systemic corticosteroids, and three $(14 \%)$ underwent cesarean section. Symptoms included fever $\left(\geq 37.5^{\circ} \mathrm{C}\right)$ in 33 patients $(79 \%)$, which was significantly more frequent in the medical intervention group. Nineteen (86\%) of the 22 patients who had a fever from days 0 to 3 and continued to have a fever from days 4 to 6 required medical intervention. 
Table 1

Characteristics and clinical information of pregnant women infected with COVID-19

\begin{tabular}{|c|c|c|c|c|}
\hline & Total & $\begin{array}{l}\text { with } \\
\text { intervention }\end{array}$ & $\begin{array}{l}\text { without } \\
\text { intervention }\end{array}$ & $P$-value \\
\hline Number & 42 & 21 & 21 & \\
\hline Age (years) & $31(20-44)$ & $31(20-44)$ & $31(20-38)$ & 0.6684 \\
\hline Gestational weeks at onset & $\begin{array}{l}25.6(4.29- \\
35.6)\end{array}$ & $\begin{array}{l}26.7(8.57- \\
35.6)\end{array}$ & $23.6(4.29-35.6)$ & 0.0781 \\
\hline $\mathrm{BMI}\left(\mathrm{kg} / \mathrm{m}^{2}\right)$ & $\begin{array}{l}21.6(15.8- \\
35.0)\end{array}$ & $\begin{array}{l}22.6(18.0- \\
35.0)\end{array}$ & $21.2(15.8-33.7)$ & 0.3924 \\
\hline $\begin{array}{l}\text { Days of admission from } \\
\text { onset }\end{array}$ & $5(-2-9)$ & $5(-2-8)$ & $5(2-9)$ & 0.8685 \\
\hline \multicolumn{5}{|l|}{ Comorbidities } \\
\hline Asthma & $2(4.76 \%)$ & $2(9.52 \%)$ & $0(0 \%)$ & 0.1473 \\
\hline Thyroid disease & $3(7.14 \%)$ & $1(4.76 \%)$ & $2(9.52 \%)$ & 0.5491 \\
\hline Others & $4(9.52 \%)$ & $2(9.52 \%)$ & $2(9.52 \%)$ & 1.0000 \\
\hline \multicolumn{5}{|l|}{ Symptoms } \\
\hline Fever $\left(\geq 37.5^{\circ} \mathrm{C}\right)$ & $33(78.6 \%)$ & $21(100 \%)$ & $12(57.1 \%)$ & 0.0007 \\
\hline Cough & $27(64.3 \%)$ & $16(76.2 \%)$ & $11(52.4 \%)$ & 0.1074 \\
\hline Nasal congestion & $17(40.5 \%)$ & $7(33.3 \%)$ & $10(47.6 \%)$ & 0.3456 \\
\hline Sore throat & $15(35.7 \%)$ & $5(23.8 \%)$ & $10(47.6 \%)$ & 0.1074 \\
\hline Dyspnea & $21(50.0 \%)$ & $15(71.4 \%)$ & $6(28.6 \%)$ & 0.0055 \\
\hline Anosmia or ageusia & $10(23.8 \%)$ & $3(14.3 \%)$ & $7(33.3 \%)$ & 0.1473 \\
\hline No symptoms & $2(4.76 \%)$ & $0(0 \%)$ & $2(9.52 \%)$ & 0.1473 \\
\hline \multicolumn{5}{|l|}{ Obstetrical complications } \\
\hline HDP & $0(0 \%)$ & $0(0 \%)$ & $0(0 \%)$ & \\
\hline TPD & $7(16.7 \%)$ & $4(19.1 \%)$ & $3(14.3 \%)$ & 0.6784 \\
\hline Oligohydramnios & $6(14.3 \%)$ & $3(14.3 \%)$ & $3(14.3 \%)$ & 1.0000 \\
\hline Fetal disorder & $2(4.76 \%)$ & $2(9.52 \%)$ & $0(0 \%)$ & 0.1473 \\
\hline
\end{tabular}

Data were shown in the median (range) or the number of patients (\%), and the bolded data had a $p$ value $<0.05$ by Mann-Whitney U test or Pearson's chi-square test, respectively. BMI, Body mass index; HDP, Hypertensive disorder of pregnancy; TPD, Threatened premature delivery. 


\begin{tabular}{|c|c|c|c|c|}
\hline & Total & $\begin{array}{l}\text { with } \\
\text { intervention }\end{array}$ & $\begin{array}{l}\text { without } \\
\text { intervention }\end{array}$ & $P$-value \\
\hline Oxygen & $13(31.0 \%)$ & $13(61.9 \%)$ & $0(0 \%)$ & $\begin{array}{l}<.0001 \\
0\end{array}$ \\
\hline Intravenous hydration & $20(47.6 \%)$ & $20(95.2 \%)$ & $0(0 \%)$ & $\begin{array}{l}<.0001 \\
0\end{array}$ \\
\hline Steroid & $10(23.8 \%)$ & $10(47.6 \%)$ & $0(0 \%)$ & 0.0003 \\
\hline Caesarean section & $3(7.14 \%)$ & $3(14.3 \%)$ & $0(0 \%)$ & 0.0723 \\
\hline
\end{tabular}

\section{Laboratory findings}

White blood cells, fraction of neutrophils, fraction of lymphocytes, platelets, LDH, D-dimer, CRP, neutrophilto-lymphocyte ratio (NLR), and platelet-to-lymphocyte ratio (PLR) [5] on days 4-6 and from day 7 onward are shown in Table 2. In the group requiring medical intervention, white blood cells and platelets were lower and LDH and CRP were higher in the both periods. The NLR and PLR were higher in the group that required medical intervention only from day 7 onward. 
Table 2

Blood parameters of pregnant women with COVID-19 associated with days from onset

\begin{tabular}{|c|c|c|c|c|c|}
\hline & Intervention & Days from onset (4 & $\leq 6)$ & Days from onset & \\
\hline \multirow{3}{*}{$\begin{array}{l}\text { Number of } \\
\text { patients }\end{array}$} & With & $\mathrm{n}=16$ & & $\mathrm{n}=20$ & \\
\hline & Without & $n=15$ & & $\mathrm{n}=21$ & \\
\hline & & Median (range) & $P$-value & Median (range) & $P$-value \\
\hline \multirow[t]{2}{*}{ WBC (cells/ $\mu \mathrm{L})$} & With & $\begin{array}{l}4650(3400- \\
7700)\end{array}$ & \multirow[t]{2}{*}{0.0397} & $\begin{array}{l}5000(3500- \\
7700)\end{array}$ & \multirow[t]{2}{*}{0.0158} \\
\hline & Without & $\begin{array}{l}5800(3200- \\
9100)\end{array}$ & & $\begin{array}{l}7000(2400- \\
9700)\end{array}$ & \\
\hline \multirow[t]{2}{*}{ Neutrophile (\%) } & With & $77.9(67.7-87.0)$ & \multirow[t]{2}{*}{0.1284} & $79.7(61.6-87.0)$ & \multirow[t]{2}{*}{0.0062} \\
\hline & Without & $74.9(45.6-85.5)$ & & $69.0(49.4-78.4)$ & \\
\hline \multirow[t]{2}{*}{ Lymphocyte (\%) } & With & $16.6(8.50-27.8)$ & \multirow[t]{2}{*}{0.4335} & $15.1(9.00-34.5)$ & \multirow[t]{2}{*}{0.0060} \\
\hline & Without & $16.9(8.00-45.1)$ & & $23.2(14.8-44.6)$ & \\
\hline \multirow[t]{2}{*}{ Platelet $\left(\times 10^{4} / \mu \mathrm{L}\right)$} & With & $15.6(11.6-20.8)$ & \multirow[t]{2}{*}{0.0008} & $16.8(10.7-28.7)$ & \multirow[t]{2}{*}{0.0057} \\
\hline & Without & $19.8(15.3-27.1)$ & & $20.2(11.0-31.5)$ & \\
\hline \multirow[t]{2}{*}{ LDH (IU/L) } & With & $181(125-391)$ & \multirow[t]{2}{*}{0.0177} & $198(139-641)$ & \multirow[t]{2}{*}{0.0013} \\
\hline & Without & $148(119-206)$ & & $156(136-227)$ & \\
\hline \multirow[t]{2}{*}{ D-dimer $(\mu \mathrm{g} / \mathrm{mL})$} & With & $1.85(0.36-4.86)$ & \multirow[t]{2}{*}{0.0187} & $1.65(0.70-8.95)$ & \multirow[t]{2}{*}{0.2404} \\
\hline & Without & $1.19(0.53-4.00)$ & & $1.42(0.38-3.42)$ & \\
\hline \multirow[t]{2}{*}{ CRP (mg/dL) } & With & $2.63(0.30-8.40)$ & \multirow{2}{*}{$\begin{array}{l}<.0001 \\
0\end{array}$} & $3.58(0.07-9.16)$ & \multirow[t]{2}{*}{$<0.0001$} \\
\hline & Without & $0.51(0.02-1.11)$ & & $0.51(0.02-2.57)$ & \\
\hline \multirow[t]{2}{*}{ NLR } & With & $4.81(2.44-10.13)$ & \multirow[t]{2}{*}{0.3814} & $5.42(1.79-8.78)$ & \multirow[t]{2}{*}{0.0057} \\
\hline & Without & $4.43(1.01-10.69)$ & & $2.97(1.11-5.26)$ & \\
\hline \multirow[t]{2}{*}{ PLR } & With & $2.26(1.09-5.15)$ & \multirow[t]{2}{*}{0.3569} & $1.97(1.00-3.43)$ & \multirow[t]{2}{*}{0.0079} \\
\hline & Without & $1.83(0.90-4.12)$ & & $1.35(0.59-2.42)$ & \\
\hline
\end{tabular}

Prediction of medical intervention based on laboratory measurements 
The AUCs for the receiver operating characteristic curve for predicting the presence or absence of medical intervention for nine blood variables, divided by the number of days since the onset, are shown in Table 3 . CRP on days 4- 6 best predicted the presence of medical intervention (AUC $=0.913$ ), with a sensitivity of $81 \%$ and specificity of $100 \%$ using a CRP cutoff of $1.28 \mathrm{mg} / \mathrm{dL}$. Platelet counts on days $4-6$ also predicted the presence or absence of medical intervention relatively well (AUC $=0.856$ ), with a sensitivity of $75 \%$ and a specificity of $87 \%$ using a platelet count cutoff of $16.3 \times 10^{4} / \mu \mathrm{L}$.

Table 3

Area under the curve of receiver operating characteristic curves of blood variables for the prediction of medical intervention

\begin{tabular}{|c|c|c|}
\hline Days from onset & $4 \leq, \leq 6(n=31)$ & $7 \leq(n=41)$ \\
\hline WBC (cells $/ \mu \mathrm{L}$ ) & 0.719 & 0.721 \\
\hline Neutrophile (\%) & 0.672 & 0.754 \\
\hline Lymphocyte (\%) & 0.590 & 0.756 \\
\hline Platelet $\left(\times 10^{4} / \mu \mathrm{L}\right)$ & 0.856 & 0.754 \\
\hline LDH (IU/L) & 0.752 & 0.794 \\
\hline D-dimer $(\mu \mathrm{g} / \mathrm{mL})$ & 0.750 & 0.608 \\
\hline CRP (mg/dL) & 0.913 & 0.873 \\
\hline NLR & 0.600 & 0.757 \\
\hline PLR & 0.605 & 0.747 \\
\hline
\end{tabular}

The bold data had AUC more than 0.8. AUC, area under the curve; CRP, C-reactive protein; LDH, lactate dehydrogenase; Lymphocyte, lymphocyte fraction; Neutrophile, neutrophile fraction; NLR, neutrophilto-lymphocyte ratio; Platelet, platelet count; PLR, platelet-to-lymphocyte ratio; WBC, white blood cell count.

\section{Relationship between CRP, gestational age, and medical intervention in the third and fourth waves}

In the third wave, five patients were admitted to the hospital, but there was no clear relationship between CRP and gestational age or the presence or absence of medical intervention (Fig. 2). In the fourth wave, 37 patients were admitted; in this group, the later the gestational age and the higher the CRP, the poorer the oxygenation and the higher the frequency of medical intervention. Pregnant women in fourth wave whose saturation of peripheral oxygen $\left(\mathrm{SpO}_{2}\right)$ was less than $93 \%$ were at more than 25 gestational weeks.

\section{Transmission of infection in the third and fourth waves}

In the third wave, no familial transmission was observed, but in the fourth wave, $57 \%$ of the cases were familial. In the fourth wave, $5(14 \%)$ infections were observed in healthcare workers. 


\section{Discussion}

This study identified early clinical factors that predict disease progression in pregnant subjects infected with SARS-CoV2 who required admission to the hospital for therapeutic intervention. To date, several laboratory findings have been reported as being associated with worse outcomes in nonpregnant subjects infected with SARS-CoV2 [5-7]. However, to the best of our knowledge, this is the first report showing laboratory measurements associated with the need for therapeutic intervention in pregnant women.

Among the laboratory indices measured, high CRP level and high platelet number were significant factors associated with the need for medical intervention (Tables 2 and 3). This is consistent with previous reports in the general population [6, 7]. In particular, CRP level days 4-6 after onset had a high sensitivity and specificity for the selection of subjects who needed treatment intervention. Based on gestational age and blood test results, a triage flow for pregnant women during the large outbreaks may be generated if designated wards are not sufficient to admit all infected pregnant women.

In the pregnant women of this study, age was not associated with need for medical intervention (Table 1). This is likely because subjects in the reproductive age range are not old, and the small age range of the women in this study (20-44 years old) did not influence the outcome. On the other hand, regardless of the age of onset of COVID-19 infection, gestational week was associated with medical intervention, which is consistent with previous report showing that SARS-CoV2 severity increases with late pregnancy in Japan [8]. This pattern of more heavily pregnant women being more severely affected has also been observed in women infected with other respiratory viruses $[9,10]$. Accordingly, the gestational week, but not the age of onset of infection, could be among the significant risk factors for severe COVID-19 in pregnant women. Regarding the symptoms experienced by pregnant women with COVID-19, those with a fever of $37.5^{\circ} \mathrm{C}$ or higher on both days $0-3$ and days $4-6$ often required medical intervention (Fig. 1). The presence of fever may be an easy marker for selecting subjects who need or will need therapeutic intervention.

In this analysis, we considered three therapeutic interventions. We understand that the meaning of medical intervention, oxygen supplementation or systemic corticosteroids or supplemental liquids due to infection-related symptoms, might include a different aspect of the disease conditions; namely, oxygen supplementation and systemic corticosteroids means the severity of pneumonia, but supplemental liquids means worsening of general condition. Regarding the necessity for hospital admission and therapeutic intervention, each intervention has a significant impact on the management of pregnant women with COVID-19.

In contrast to low familial infection rate early in 2020 [12], as shown in Fig. 3, 57\% of the patients in the fourth wave were infected by family members. It has been reported that almost all SARS-CoV2 infections in the fourth spike were caused by the N501Y mutant, which is more contagious than the previous serotype [2]. Considering the low vaccination rate in Japan compared with those of other developed countries in end of June 2021(https:// ourworldindata.org/covid-vaccinations), caution is warranted, and 
another large outbreak could occur in the near future. Therefore, our study might help medical professionals prioritize pregnant women who should be hospitalized if there is a fifth wave of infections.

This study has several limitations. First, this is a retrospective study at a single center. Second, the number of participants in this study was small, although nearly all of the pregnant women positive for SARS-CoV2 who were diagnosed in Sapporo City during the third and fourth spikes were analyzed. Third, confounding factors that may affect the COVID-19 severity and related mortality, such as smoking or comorbidities, were not obtained for all subjects.

\section{Conclusions}

This study summarizes the clinical characteristics of pregnant women positive for SARS-CoV2 who were admitted to our hospital. Subjects with a fever of $37.5^{\circ} \mathrm{C}$ or higher on both days $0-3$ and days $4-6$ often required medical intervention. Serum CRP value on days $4-6$ cut off of $1.28 \mathrm{mg} / \mathrm{dL}$ is a valuable parameter for the decision of hospital admission. The results of this study provide a guide for the management of infected pregnant women during future outbreaks of SARS-CoV2 and could potentially be used to inform decisions on the triage and hospitalization of these women.

\section{Abbreviations}

AUC Area under the curve

COVID-19 Coronavirus disease 2019

CRP C-reactive protein

LDH Lactate dehydrogenase

NLR Neutrophil-to-lymphocyte ratio

PLR Platelet-to-lymphocyte ratio

$\mathrm{SpO}_{2}$ Saturation of peripheral oxygen

\section{Declarations}

\section{Ethics approval and consent to participate:}

This study was approved by the Institutional Review Board of Hokkaido University Hospital and conformed to the principles of Declaration of Helsinki.

Consent for publication: Not applicable. 
Availability of data and material: The datasets cannot be made publicly available due to ethical restrictions by the Institutional Review Board of Hokkaido University Hospital. Please contact the corresponding author to consider the data set disclosure.

Competing interest: None declared.

Funding: This study was supported by a Grant-in Aid for Scientific Research from the Ministry of Education, Science, Sports, and Culture of Japan (No. JP19K1865709), and Hokkaido University Center of Innovation (JST COI Grant Number JPMJCE1301). This work was not associated with any commercial entity.

Author contributions: All authors, RY, HA, TU, MT, KN, YS, KN, KC, SN, YN, SK, and HW participated in the design of the study and collected data on each pregnant patients that participated in this study. RY, HA, TU, SK participated in design of the study, RY, HA, TU, and SK performed statistical analyses, and drafted the manuscript. SK and HW conceived of the study, and participated in its design and coordination, and helped to draft the manuscript. All authors have read and approved the manuscript.

\section{Acknowledgments}

Administrative support was obtained from the Bureau of Regional Medical Service Promotion, Department of Health and Welfare of the Hokkaido Government, and Sapporo City Health Center.

\section{References}

1. Hattori T, Saito A, Chiba H, Kuronuma K, Amishima M, Morinaga D, et al: Characteristics of COVID-19 patients admitted into two hospitals in sapporo, Japan: Analyses and insights from two outbreak waves. Respir Investig. 2021;59(2):180-186.

2. Leung K, Shum MH, Leung GM, Lam TT, Wu J. Early transmissibility assessment of the N501Y mutant strains of SARS-CoV-2 in the United Kingdom, October to November 2020. Euro Surveill. 2021; 26(1): 2002106.

3. City of Saporo. Status of covid-19 outbreaks in the city (statistical information). Available from: https://www.city.sapporo.jp/hokenjo/f1kansen/2019ncovhassei_toukei.html. (Accessed 19 June 2021)

4. The Japan Society of Obstetrics and Gynecology. Novel coronavirus vaccine. Available from: http://www.jsog.or.jp/news/pdf/20210617_COVID19.pdf. (Accessed 19 June 2021)

5. Chan AS, Rout A. Use of Neutrophil-to-Lymphocyte and Platelet-to-Lymphocyte Ratios in COVID-19. J Clin Med Res. 2020; 12(7):448-453.

6. Ayanian S, Reyes J, Lynn L, Teufel K. The association between biomarkers and clinical outcomes in novel coronavirus pneumonia in a US cohort. Biomark Med. 2020; 14(12):1091-1097.

7. Muhammad R, Ogunti R, Ahmed B, Munawar M, Donaldson S, Sumon M, et al. Clinical Characteristics and Predictors of Mortality in Minority Patients Hospitalized with COVID-19 Infection. 
J Racial Ethn Health Disparities. 2021; doi: 10.1007/s40615-020-00961-x.

8. Hayakawa S, Komine-Aizawa S, Takada K, Kimura T, Yamada H. Anti-SARS-CoV-2 vaccination strategy for pregnant women in Japan. J Obstet Gynaecol Res. 2021; 47(6):1958-1964.

9. Goodnight WH, Soper DE. Pneumonia in pregnancy. Crit Care Med. 2005; 33(10 Suppl):S390-397.

10. Mertz D, Geraci J, Winkup J, Gessner BD, Ortiz JR, Loeb M. Pregnancy as a risk factor for severe outcomes from influenza virus infection: A systematic review and meta-analysis of observational studies. Vaccine. 2017; 35(4):521-528.

11. Contact Tracing during Coronavirus Disease Outbreak, South Korea, 2020.

12. Park YJ, Choe YJ, Park O, Park SY, Kim YM, Kim J, et al. COVID-19 National Emergency Response Center, Epidemiology and Case Management Team. Emerg Infect Dis. 2020;26(10):2465-2468.

\section{Figures}

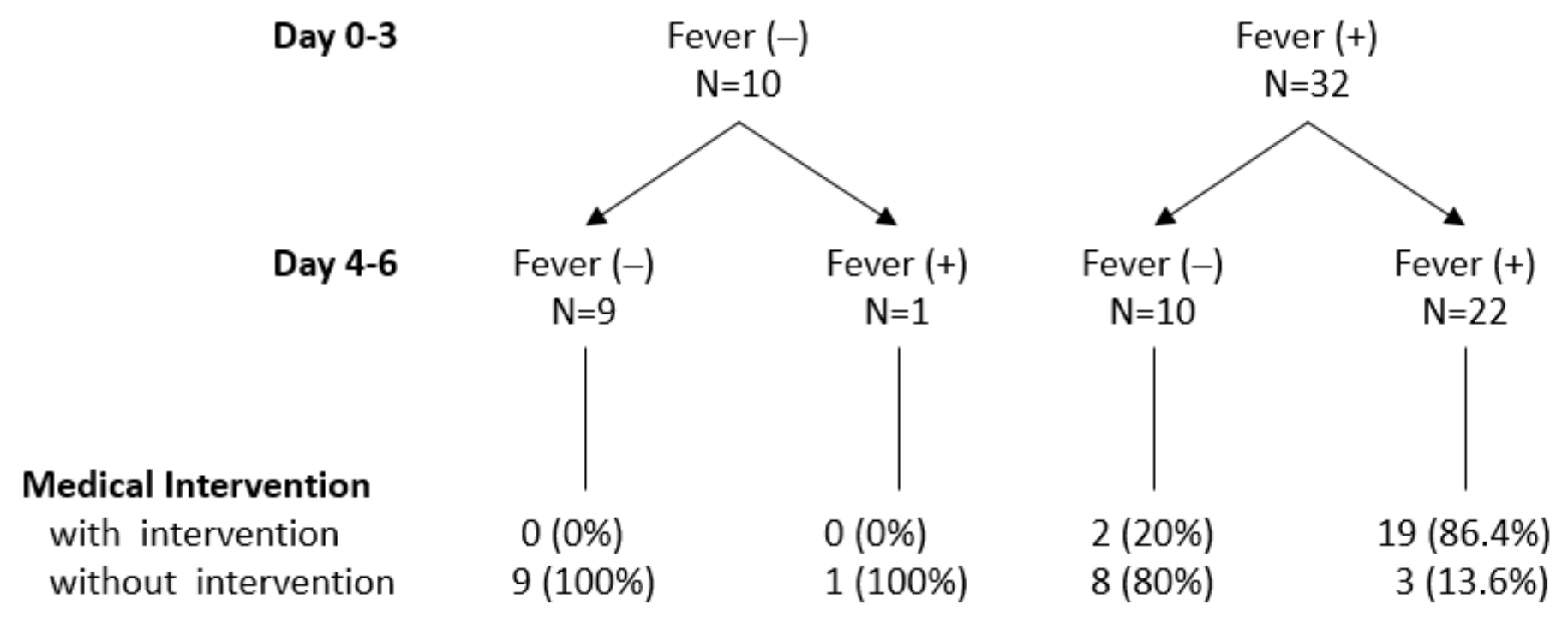

\section{Figure 1}

Relationship between the presence of fever and need for medical intervention Fever was defined as $37.5^{\circ} \mathrm{C}$ or higher. Nineteen ( $86 \%$ ) of the 22 patients who had a fever from days 0 to 3 continued to have a fever on days 4-6 and required medical intervention. 


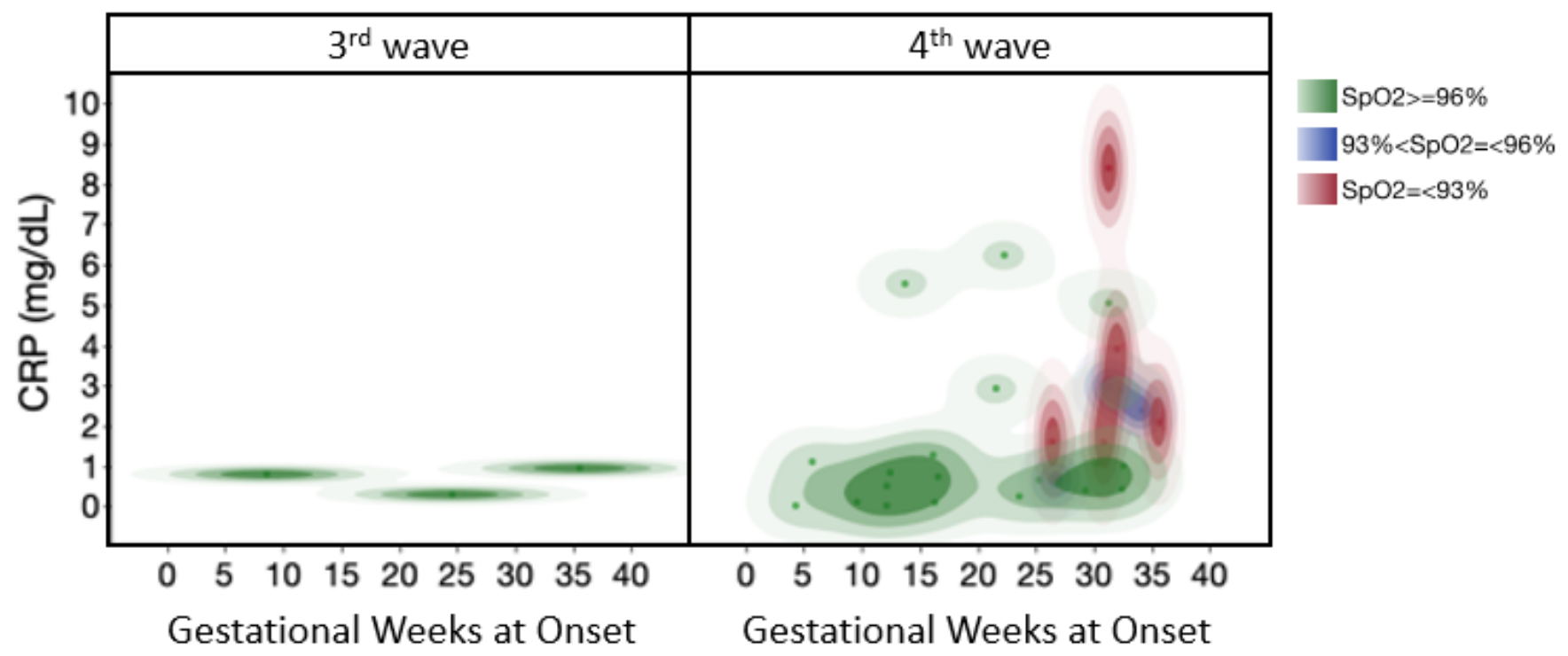

B

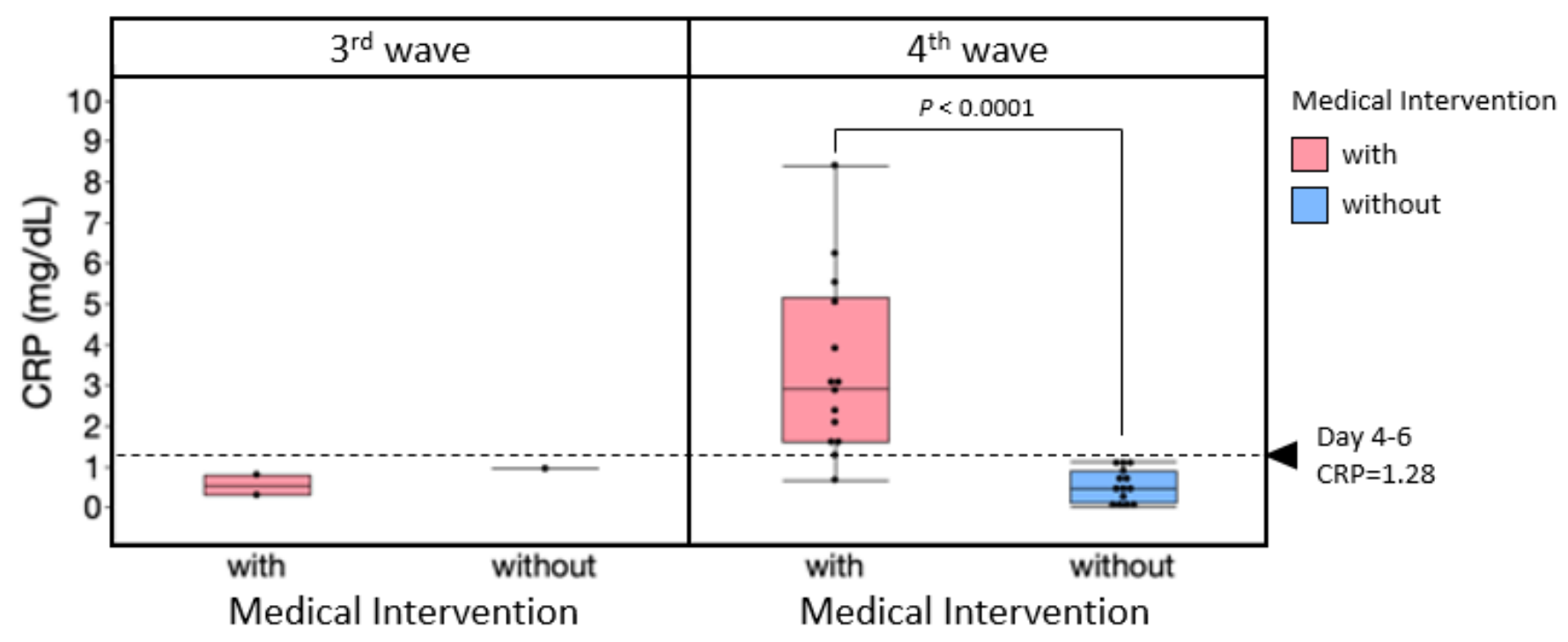

Figure 2

Relationship between C-reactive protein, gestational age, and the need for medical intervention A) Relationship between C-reactive protein, gestational age, and saturation of peripheral oxygen in the third and fourth spikes. B) Relationship between C-reactive protein and the need for medical intervention in the third and fourth spikes. 


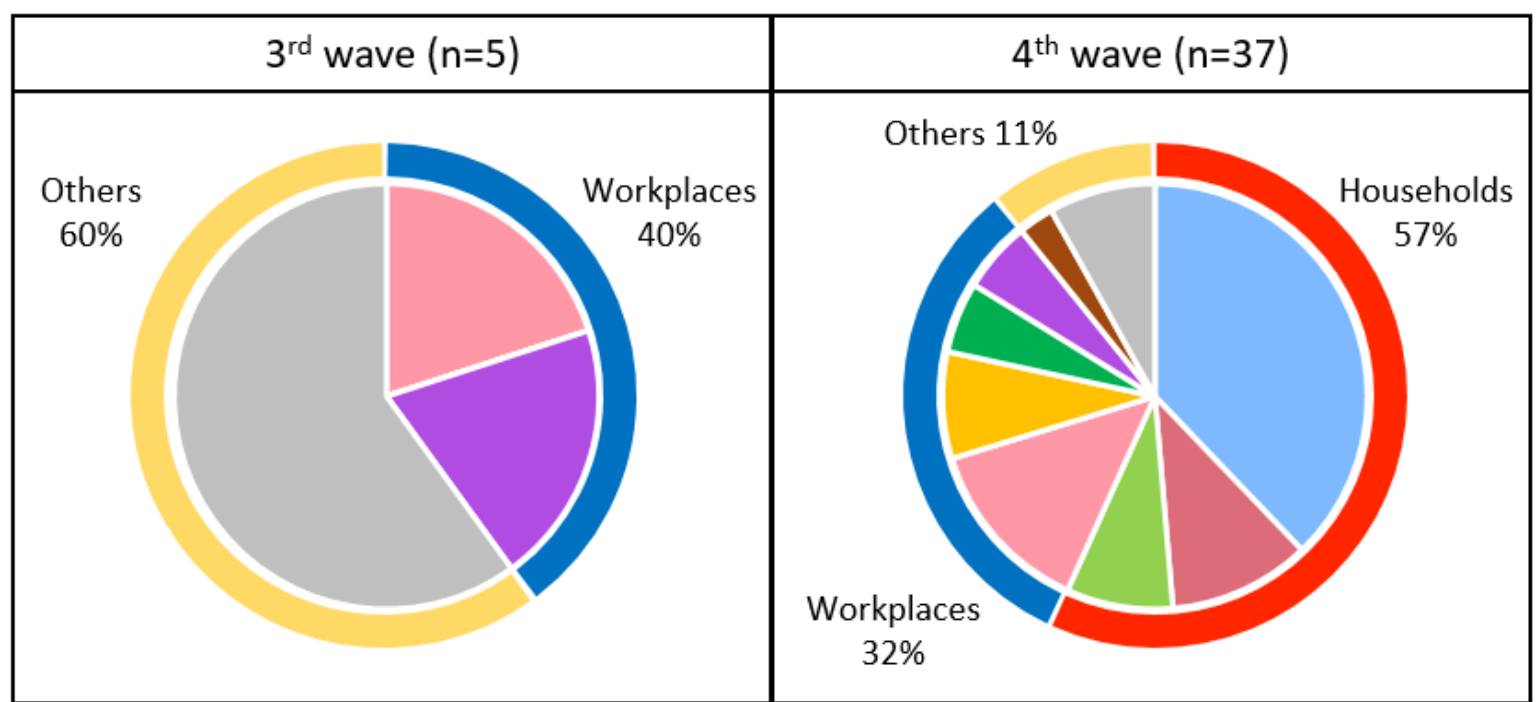

Partner Mother

$\square$ Other family members

$\square$ Hospital

$\square$ Nursery school

Beauty business

Other workplaces

Group activities

Unknown

Figure 3

Sources of infection of COVID-19 in the third and fourth spikes 